\title{
In memory of Narinder Singh Kapany
}

The Indian scientist and passionate entrepreneur responsible for pioneering work on optical fibres and biomedical optics has passed away aged 94 .

N arinder Singh Kapany is considered by many as the unsung hero and father of fibre optics, with his diverse pioneering achievements in the area arguably not receiving the level of recognition that they truly deserve. Kapany was one of the first physicists to demonstrate that a bundle of fine glass fibres could transmit high-resolution images, and performed many early experiments to investigate the physics of coupling and propagation of light in fibres ${ }^{1-3}$. In biomedical optics, he designed fibre-optic hypodermic probes for imaging of living human tissue ${ }^{4}$, conducted early experiments to cure retinal detachment with lasers ${ }^{5}$ and also demonstrated optical oximetry of blood ${ }^{6}$. He also designed key components for fibre-optics-based communication systems ${ }^{7}$ and made pioneering contributions in solar energy. Kapany died in Redwood City, California, USA, on 4 December 2020, aged 94.

Today, optical fibres are indispensable to a wide variety of fields. They form the backbone of optical data transmission systems that carry the Internet around the world, and generate and guide intense laser light for tasks in material processing, biomedicine diagnostics and laser surgery $^{8}$. Fibres also play a critical role in spectroscopy and optical sensing of chemical and biological substances. The genesis of the field of fibre optics owes much to Kapany, who was not only responsible for many scientific papers and patents in the area but also authored the first comprehensive book on the topic (Fiber Optics: Principles and Applications) in 1967.

Kapany was born in Moga, Punjab, India, on 31 October 1926 and his early schooling took place in Dehradun, a beautiful city in the foothills of the Himalayas. His career first started with employment in a local ordinance factory where he designed and fabricated optical instruments before moving to London in the early 1950s for his higher studies. He undertook a $\mathrm{PhD}$ at Imperial college in London, UK, during which he experimented with micrometre-diameter optical fibres for image transmission and fabricated a flexible fibrescope ${ }^{1}$ - a precursor to modern endoscopes.

After receiving his $\mathrm{PhD}$ in 1955 he relocated to the United States, where he stayed for the remainder of his life, working

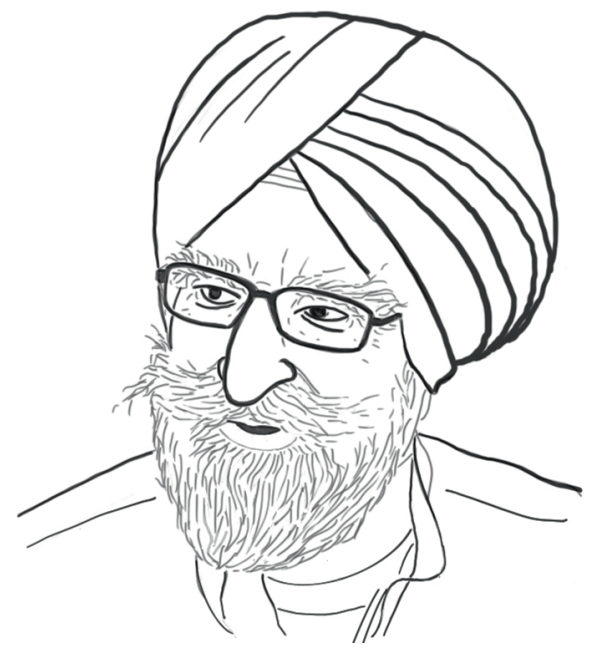

A line sketch of N. S. Kapany.

in both academia and industry. He first spent time on the east coast at the University of Rochester and the Illinois Institute of Technology before in 1960 moving to California to found several business ventures and conduct research at the University of California at Santa Cruz.

Ever since his schooldays, Kapany had been curious about the idea of bending the propagation of light and using it for imaging and medical applications. His interests resonated well with his $\mathrm{PhD}$ supervisor in London, Harold Hopkins, who advised him to experiment with a bundle of glass cylinders. Kapany worked tirelessly to assemble a coherent bundle of hundreds of glass fibres with a diameter of a few tens of micrometres and used them to build a flexible fibrescope for transmitting images that was described in a paper published with Hopkins in Nature on 2 January $1954^{1}$. The work was simultaneously published alongside a paper by Abraham Cornelius Sebastiaan van Heel from Delft, the Netherlands, describing similar research on fibre-based light transmission ${ }^{9}$, and the two papers inspired the development of modern fibre endoscopes.

Kapany went on to devise ingenious ways to characterize quality of optical fibre during the fabrication using optical interferometry ${ }^{10}$. He also designed apparatus to fabricate a glass fibre with a cladding, a technique still used to produce modern fibres commercially.
While less well known, Kapany's contributions to push the frontiers of biology and biomedical optics were also crucial. Following the invention of the laser in 1960, he promptly systematically studied the interaction between green and infrared laser pulses and the eye's retina, resulting in the ability to laser weld a detached retina to the eye's choroid in the early 1960s to cure retinal blindness ${ }^{5}$. He was also one of the first scientists to design a fibre-optics-based scheme for optical oximetry of blood ${ }^{6}$, which measures the level of oxygen saturation in blood via its optical absorption characteristics. Optical pulse oximetry has since evolved to become a routine and important optical technique today.

Still fascinated by the potential for image transmission through optical fibres, Kapany later used pulsed light sources to transfer a three-dimensional image $\mathrm{e}^{11,12}$ and performed extensive analysis of point-spread functions and image assessment parameters in optical systems ${ }^{3}$. These early works paved the way to modern engineering tools for laser ranging, laser-scanning and distance measuring tools.

Kapany also had interest in harnessing solar energy for practical applications. He improved design of efficient solar panels that can be mounted on walls or windows, and obtained several patents for apparatus for solar window and solar walls for cooling an environment ${ }^{13}$.

After early experiments around 1960, the experimental work on fibre optics had virtually stopped; both Hopkin and van Heels abandoned the field but Kapany remained steadfast. He continued with his passion of image transmission, biomedical instrumentation and sensors using fibre optics throughout his career.

After highly transparent fibres were fabricated in the 1960s by Charles Kao ${ }^{14}$, who received the 2009 Nobel Prize in Physics for his achievements, Kapany was instrumental in making technological innovations such as fibre couplers, (de-) multiplexers and amplifiers to push forward optical fibre optical communication system ${ }^{7}$. He had about 100 patents and a similar number of publications.

Kapany was a passionate entrepreneur who launched several companies related to optical technologies as well as the commercialization of optical 
instrumentation, notably Optics Technology in 1960, Kaptron in 1973 and K2 Optronics in 2000 .

When asked about why he named his company K2 Optronics after the second highest mountain in the world, "one must be modest" was his reply. He also made donations to support the creation of scientific chairs at institutions and contributed generously for spreading Indian culture through his unique collection of paintings and arts.

The passion, creativity and practical instrumentation skills of Kapany were extraordinary. He remained indefatigably enthusiastic about science, innovation and entrepreneurship, and continued working into his late 80 s. His curiosity of bending light changed the course of history.

Kamal P. Singh $ه$

Department of Physical Sciences, Indian Institute of Science Education and Research Mohali, Manauli, Punjab, India.

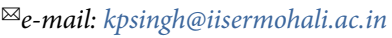

Published online: 21 April 2021

https://doi.org/10.1038/s41566-021-00812-z
References

1. Hopkins, H. \& Kapany, N. S. Nature 173, 39-41 (1954)

2. Kapany, N. S. Nature 184, 881-883 (1959)

3. Kapany, N. S. Nature 188, 1083-1086 (1960)

4. Capellaro, D., Kapany, N. S. \& Long, C. Nature 191, 927-928 (1961).

5. Kapany, N. S., Peppers, N. A., Zweng, H. C. \& Flocks, M. Nature 199, 146-149 (1963)

6. Kapany, N. S. \& Silbertrust, N. Nature 204, 138-142 (1964).

7. Kapany N. S. \& Unterleitner, F. C. US patent 4,479,697 (1984)

8. Fermann, M. \& Hartl, I. Nat. Photon 7, 868-874 (2013).

9. van Heel, A. C. S. Nature 173, 39 (1954).

10. Reiffel, L. \& Kapany, N. S. Rev. Sci. Instrum. 31, 1136 (1960).

11. Kapany, N. S. Proc. SPIE https://doi.org/10.1117/12.953588 (1973).

12. Kapany, N. S. US patent 3,682,553 (1972).

13. Kapany, N. S. \& Hintzke, M. A. US patent application $13 / 050,887$ (2012).

14. Kao, K. C. \& Hockham, G. A. Proc. IEE 113, 1151-1158 (1966) 